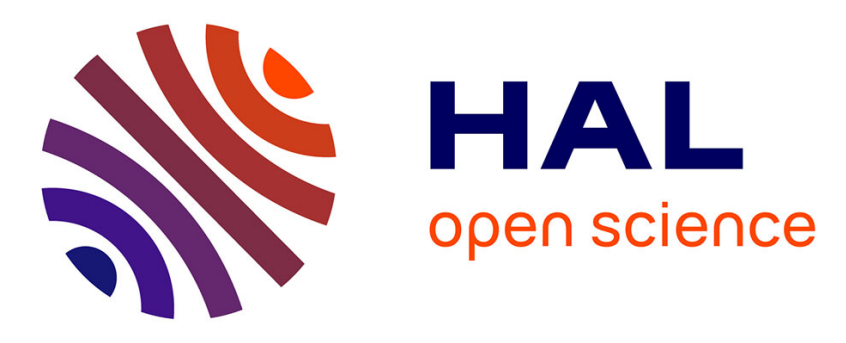

\title{
Estimating the energy repartition in micro electrical discharge machining
}

Samuel Bigot, Gianluca d'Urso, Jean-Philippe Pernot, Cristina Merla, Anthony Surleraux

\section{- To cite this version:}

Samuel Bigot, Gianluca d'Urso, Jean-Philippe Pernot, Cristina Merla, Anthony Surleraux. Estimating the energy repartition in micro electrical discharge machining. Precision Engineering, 2016, 43, pp.479485. 10.1016/j.precisioneng.2015.09.015 . hal-01403323

\section{HAL Id: hal-01403323 \\ https://hal.science/hal-01403323}

Submitted on 25 Nov 2016

HAL is a multi-disciplinary open access archive for the deposit and dissemination of scientific research documents, whether they are published or not. The documents may come from teaching and research institutions in France or abroad, or from public or private research centers.
L'archive ouverte pluridisciplinaire HAL, est destinée au dépôt et à la diffusion de documents scientifiques de niveau recherche, publiés ou non, émanant des établissements d'enseignement et de recherche français ou étrangers, des laboratoires publics ou privés. 


\title{
Estimating the energy repartition in micro electrical discharge machining
}

\author{
Samuel Bigot ${ }^{\mathrm{a}}$, Gianluca D’Urso ${ }^{\mathrm{b}}$, Jean-Philippe Pernot ${ }^{\mathrm{c}}$, Cristina Merla ${ }^{\mathrm{b}, *}$, \\ Anthony Surleraux ${ }^{\mathrm{a}, \mathrm{c}}$ \\ a Cardiff School of Engineering, Cardiff University, Cardiff CF24 3AA, UK \\ ${ }^{\mathrm{b}}$ Dipartimento di Ingegneria Gestionale, dell'Informazione e della Produzione - DIGIP, Università degli Studi di Bergamo, 24044 Dalmine, BG, Italy \\ ${ }^{c}$ Arts et Métiers ParisTech, LSIS - UMR CNRS 7296, Aix-en-Provence, France
}

Keywords:

Micro-EDM

Die sinking

Energy measurement

\begin{abstract}
A B S T R A C T
This paper presents a new approach for the recording of the total quantity of energy exchanged during the micro electrical discharge machining (EDM) process. In particular, this approach allows for the estimation of the percentage of energy absorbed by the two electrodes (tool and workpiece) using a combination of theoretical models and experimental results, thanks to an advanced discharges measuring approach. An experimental campaign was executed on a Sarix SX200 micro-EDM machine with a tungsten carbide tool electrode. In particular, the process was analyzed for two different electrode shapes, a triangular and a rectangular based parallelepipeds, and two sets of machining parameters. After the execution of the experimental campaign it estimate the total amount of energy that occurred during the entire die sinking process. The energy effectively lost into the tool, into the workpiece and into the dielectric was estimated from the measurement of the volume of material actually removed both from the tool and from the workpiece. The preliminary results appears to fit those presented in the literature and the validity of several theoretical crater models was then assessed. The validation of the presented acquisition method could enable the use of information related to energy repartition in the simulation of the micro-EDM process.
\end{abstract}

\section{Introduction}

Micro-EDM (electrical discharge machining) can be considered as one of the most promising non-conventional micro-machining techniques due to its ability to machine high aspect ratio micro holes as well as complex 3D shapes in any conductive material [1-3].

The technology behind EDM consists in two electrodes (also known as the tool and the workpiece) that are immerged in a dielectric fluid and submitted to an electrical current. As the distance between the electrodes diminishes, the open gap voltage increases until it reaches the breakdown voltage of the dielectric at which point a discharge occurs. The distance corresponding to that breakdown voltage is known as the machining or sparking gap.

The discharge consists of a plasma channel that forms between the two electrodes and transfers thermal energy to them.

\footnotetext{
* Corresponding author at: University of Bergamo - DIGIP, Viale Marconi 5, 24044 Dalmine, BG, Italy. Tel.: +39 035 2052330; fax: +39 0352052043.

E-mail address: cristina.merla@unibg.it (C. Merla).
}

The heating of the metal leads to its vaporization and melting. After the discharge has taken place, a single or multiple craters are left on the electrodes' surfaces. Due to the directional nature of the process (determined by the current polarity) the crater dimensions on the tool and the workpiece differ.

The formation of these craters is due to the collapse of the plasma channel after the spark that creates a depression. Even though part of the melted material is extracted and evacuated by the dielectric and accounts for the presence of debris, a nonnegligible part of the melted material remains.

The process is influenced by numerous parameters such as the electrical parameters (voltage, current, frequency, etc.), the dielectric's characteristics or the material properties that will determine the machining performance in terms of surface roughness or material removal rate [4].

A lot of attempts have been made in order to model the microEDM process. It is possible to affirm that the main elements considered in the majority of the models are the cathode, the anode and the plasma channel between them. An assumption regarding the energy distribution considers that part of the energy goes to the tool and workpiece while the rest is lost in the dielectric. Despite 
this assumption, a lack of information about the micro-EDM effective amount of energy transferred to the workpiece emerges from the literature. Several papers deal with the EDM energy distribution, but not much work has been performed referring to the micro scale process. Shao and Rajurkar [5] determined the pulse energy distribution ratio in the micro-EDM erosion process. In other words, the distribution of the total energy of a pulse into each electrode and the inter-electrode gap was determined, based on the dimensions of the craters left on the tool and on the workpiece by the electric discharges. It was demonstrated that the average pulse energy distribution is $9.4 \%$ to the anode and $3.6 \%$ to the cathode. Zahiruddin and Kunieda [6], based on an experimental campaign, estimated the percentage of material which is vaporized or melted during the machining process. This percentage was demonstrated to be different for the anode and for the cathode.

Obaciu et al. [7] made a comparison between the machining of so called "common" materials, in other words homogeneous materials like steel, and heterogeneous materials like polycrystalline diamond. Regarding the energy measurement, it was possible to demonstrate that the energy density increases with the pulse on time although it is not possible to find the same trend for both materials. In [8] the energy distribution was determined from the temperature state of the material. A certain number of assumptions related to the types of thermal transfers were made. Relations between process parameters (polarity, discharge duration, dielectric fluid and peak current) and energy distribution were investigated.

A few attempts have been made in order to measure the number of spark discharges and the amount of energy exchanged during the micro-EDM machining process. For example, Bissacco et al. [9], while investigating the micro-EDM milling process, estimated the amount of discharges in order to carry out a real time wear compensation method based on the discharge population characterization. Similarly, Mahardika and Mitsui [10] estimated the number of discharges occurring during the process and presented an innovative model for the estimation of the total energy exchanged during the machining. Regarding the amount of energy exchanged during the process, in [11-13] the authors made an estimation of the amount of energy effectively absorbed by the electrodes. In [14] it is demonstrated that during the EDM process the amount of energy effectively absorbed by the workpiece is between 6.5 and $17.7 \%$, depending on the process parameters.

A lack of information related to the exact amount of energy absorbed by the electrodes emerges from the literature. The majority of the models deals with a thermal approach to the material removal mechanism of the EDM process: these are based on partial differential equations in cylindrical coordinates describing the heat transfer between tool and workpiece. The thermal phenomenon is considered by the majority of the authors as the main one having an influence on the material removal mechanism: based on this assumption, the energy is transferred from the tool to the workpiece and it is partially dissipated into the dielectric fluid or into the plasma channel itself.

Di Bitonto et al. [15,16] presented a cathode and an anode erosion model. The cathode model is based on the concept of fraction of energy effectively converted into removed material and it is demonstrated that the model tends to overestimate the removed volume of the crater and the removal rates as well. In $[17,18]$ the authors have modeled the EDM process considering two semi-infinite bodies, representing the workpiece and the electrode, separated by a certain gap crossed by a heat disk representing the plasma heating phenomenon. The process is modeled by a partial differential equation with some boundary assumptions related to the workpiece insulation. It is demonstrated that the diameter of the plasma channel evolves during the process and the temperature during the machining time remains constant, equal to the boiling temperature of the electrode.

In several papers the authors have adopted a thermal approach to describe the micro-EDM erosion process and to predict the final geometry of the crater. Based on this approach a fixed amount of electrical energy is converted into thermal energy resulting in the melting and/or vaporizing of the material composing the workpiece. In [19] the thermal model is used to numerically calculate the profile of the craters left by the sparks. In [20] the authors developed a numerical model for predicting the temperature distribution and the residual stresses resulting from a single spark discharges EDM process. In [21] the authors considered the effect of the residual stresses, suggesting that one of the most important factors in EDM machining is the electrostatic force occurring between the tool and the workpiece. It was demonstrated that the stresses caused by the electrical field are independent from the spark dimensions and durations. In [22] the authors based the analysis on the heat transfer equation which was solved numerically. In particular, the effect of current, duty cycle, discharge duration and voltage was investigated. In [23] a finite elements model aimed at describing and predicting the temperature fields generated by a multiple discharges process within the workpiece was developed. The solution of the thermal problem led to the temperature distribution inside the workpiece from which it was possible to estimate the shape of the craters. Once the temperature distribution was found, the criterion for the estimation of the crater volume was set: every part of the workpiece which reached a temperature higher than the equivalent temperature is supposed to be removed from the workpiece.

The aim of this paper is to implement a new procedure and experimental set up aimed at assessing the total amount of energy occurring during micro-EDM and its percentage absorbed by the workpiece, by the tool and lost in the dielectric.

For this purpose, after a review of existing theoretical EDM models with the aim of assessing their ability to predict volume removal in the scope of micro-scale EDM, a selection of two specific models was carried out. Then, a section was dedicated to explain how sparks information were acquired and analyzed in order to estimate the total amount of energy produced during the EDM experiments. Finally, the last section describes an experimental campaign which was performed to demonstrate how the energy distribution between workpiece, tool and dielectric could be estimated.

\section{Thermal models for micro-scale}

The proposed objective here is to determine whether or not those models developed for EDM apply on a micro-scale considering the proportion of energy that is actually delivered to the electrodes. Most of the models include a coefficient in their formulation of the heat flux to take into account the fact that energy is lost during the process notable through the dielectric fluid. However the used values seem high (40-50\%) when considering the case of micro-EDM $(<10 \%)$.

After the collection of all the physical models, a selection of the thermal ones was carried out. In particular two main models were selected (Di Bitonto et al. [15] and Beck et al. [24]) based on the heat transfer equation formulation. The initial heat transfer equation is reported in Eq. (1):

$$
\frac{\partial T}{\partial t}-\alpha \nabla^{2} T=0
$$

where $T$ is the temperature (in kelvin), $t$ the time (in seconds), $\nabla^{2}$ is the Laplace operator and $\alpha$ is the thermal diffusivity $\left(\mathrm{m}^{2} \mathrm{~s}^{-1}\right)$. It is important to consider that the heat equation is written with the Laplace operator to make the equation general for any coordinate 
Table 1

Input and initial assumptions of the thermal models.

\begin{tabular}{lll}
\hline Input & Description & Value \\
\hline$K_{t}$ & Thermal conductivity $[\mathrm{J} / \mathrm{s} \mathrm{m} \mathrm{K}]$ & 220 \\
$\rho$ & Material density $\left[\mathrm{kg} / \mathrm{m}^{3}\right]$ & 2700 \\
$C_{p}$ & Specific heat $[\mathrm{J} / \mathrm{kg} \mathrm{K}]$ & 910 \\
$T_{i}$ & Initial temperature $[\mathrm{K}]$ & 293 \\
$T_{b}$ & Boiling temperature $[\mathrm{K}]$ & 2792 \\
$\alpha$ & Thermal diffusivity $\left[\mathrm{m}^{2} \mathrm{~s}^{-1}\right]=K_{t} / \rho C_{p}$ & $8.95 \times 10^{-5}$ \\
$R_{0}[16]$ & Radius of the insulated surface of the & 0.0041 \\
& workpiece $[\mathrm{m}]=50 R_{c}$ & \\
$R_{c}[16]$ & Heat source radius at the cathode surface & $8.23 \times 10^{-5}$ \\
& {$\left[\right.$ m] $=0.778 \times t_{i}^{(3 / 4)}$} & 3.6 \\
$w_{t}$ & Percentage of energy absorbed by the tool [\%] & 5 \\
\hline
\end{tabular}

system. The studied models provide a temperature distribution in the workpiece under different assumptions mainly concerning the heat flux that is the plasma channel forming between both electrodes. In order to assess the validity of said models on a microscale, a comparison between predicted and experimental crater shapes was done. As an example, Di Bitonto's model is summarized in Eq. (2):

$T(r, t)=T_{0}+\frac{F_{c} u_{e} i_{e}}{k_{t} 2 \pi r_{0}} \cdot \operatorname{erfc} \frac{r}{2 \sqrt{\alpha t}}$

where $r$ is the radial distance from the heat source (in meters), $T_{0}$ is the initial temperature (in kelvins), $k_{t}$ is the thermal conductivity $\left(\mathrm{W} \mathrm{m} \mathrm{m}^{-1} \mathrm{~K}^{-1}\right.$ ), erfc is the complementary error function, $F_{c}$ is the fraction of energy transferred to the cathode, $u_{e}$ is the discharge voltage (in volts), $i_{e}$ is discharge current $(A)$ and $r_{0}$ is the radius of the cylindrical workpiece that is considered.

A very similar formulation of the thermal distributions was taken into account for the models. Based on these thermal equations, it was possible to plot the thermal distribution into the workpiece allowing the collection of information about the temperatures reached during the machining.

Instead of using the coefficients provided by the various authors in their models, energy distributions values for micro-EDM available in Shao and Rajurkar [5] were used. A value for $t_{i}$ (pulse duration) was selected in accordance with experimental data. All chosen model input values are presented in Table 1. Figs. 1 and 2 show an example of the temperature distribution in Beck's and Di

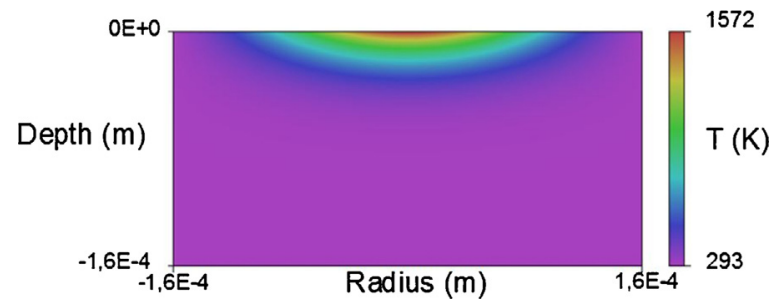

Fig. 1. Temperature distribution in Beck's model.

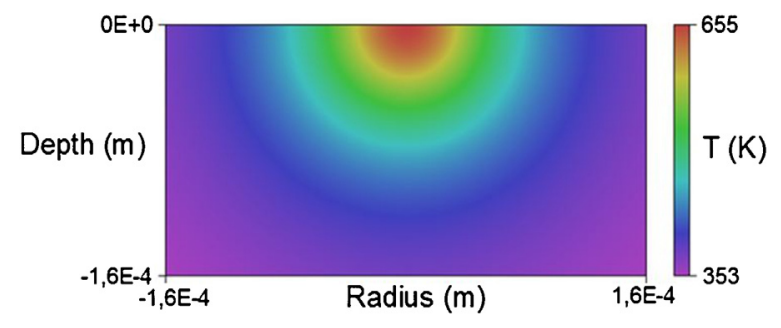

Fig. 2. Temperature distribution in Di Bitonto's model.
Bitonto's models respectively (the time of the temperature distribution is $5 \mu \mathrm{s}$ ).

While the disparity between both models in terms of distribution shape and amplitude is not surprising due to the very different assumptions that were made in each case, it is noticeable that the maximum temperature reached in the material does not attain the melting temperature, even less so the boiling one.

Good results were obtained previously in the case of macroscale EDM for the prediction of crater dimensions by these models. In the case of micro-EDM, however, the models' validity can be put into question here. A proposed solution to adapt said models to the micro-EDM context would be to apply a scaling coefficient to the temperature distribution. However, it is unlikely that a single value for that coefficient would be relevant to all materials and a wide-range of machining parameters.

Following this observation, theoretical crater models will not be used for the analysis of the following experimental campaign. Instead relations based on the specific heat of the involved materials will be used.

\section{Sparks information acquisition}

\subsection{Data collection automation}

The gap voltage and current waveform were acquired during the experimental campaign using a Tektronix digital oscilloscope. The connection between the Sarix SX200 machine and the oscilloscope was achieved through the use of a current probe for the measurement of the current and two wires connected to both polarities of the machine. The Tektronix oscilloscope's operating system being Windows ${ }^{\circledR}$, it was possible to use Matlab ${ }^{\circledR}$ directly on the oscilloscope without the need of a connection to a personal computer.

A software toolbox was developed in order to have a semiautomatic recording of EDM single discharges. It automatically carried out the setting up of the oscilloscope according to the machine parameters and launched a series of data acquisitions, during which each EDM test allowed for the recording of limited patches of discharges at regular times, as described below.

A VISA (Virtual Instrument Standard Architecture) object in Matlab ${ }^{\circledR}$ associated with the GPIB (General-Purpose Interface Bus) controller supported the communication with the oscilloscope. The input buffer size limited the amount and precision of discharges that could be recorded in each patch. It had to be large enough to contain enough discharge records while still being able to be transferred in a short amount of time, allowing for enough records to be spread evenly throughout the erosion process. The input buffer size was set to a value equal to $12,000,000$ bytes, which was considered a good compromise between speed and quantity of information exchange. It allowed for the recording of $0.5 \mathrm{~s}$ of discharges every $20 \mathrm{~s}$.

An important point resides in the fact that the data capture of both channels (current and voltage) can only be performed sequentially and not simultaneously. In order to be sure that both channels were synchronized, a falling edge trigger was set on the oscilloscope with a holding time of seven seconds.

Each $0.5 \mathrm{~s}$ patch contained $10,000,000$ points, which gave sufficient resolution on the voltage and current waveforms recorded by the oscilloscope. Matlab ${ }^{\circledR}$ was then used to read and transfer the binblock data, which was saved into a ".mat" format file for further investigation.

\subsection{Data analysis}

The analysis of ten millions points at the same time requested a segment of memory from the operating system (32-bits) that was 
larger than what was available. For this reason, the points matrix was divided into five sub-parts. The process limit of the operating system was $3 \mathrm{~GB}$.

Before any further analysis, the data was filtered using a lowpass filter in order to reduce the signal noise.

The search for discharges is made while considering both channels at the same time. A discharge is considered to start at a point where the voltage is below a certain threshold of the process nominal voltage and the current to be above a set value. The discharge ends when the current goes below another set value.

It was then possible to calculate the following parameters: discharge voltage $\left(u_{e}\right)$; discharge current $\left(i_{e}\right)$; pulse duration $\left(t_{i}\right)$; discharge duration $\left(t_{e}\right)$; ignition delay time $\left(t_{d}\right)$; discharge energy $W_{e}$.

By multiplying the discharge voltage by the discharge current and then integrating it during the discharge duration $\left(t_{e}\right)$, it was possible to estimate the amount of energy produced by each spark.

\section{Experimental campaign}

The experimental campaign was executed on a Sarix SX200 micro-EDM machine with a tungsten carbide tool electrode. In particular, two different tool shapes were used, a triangular and a rectangular based parallelepipeds as described in Fig. 3. Those shapes were realized by means of a wire-EDM machine (AGIE AgieCut Vertex) using a $\varnothing 100 \mu \mathrm{m}$ wire. The dimensions of the tool features are reported in Table 2 (in both cases the thickness of the electrode was equal to $2.5 \mathrm{~mm}$ ), while the physical and thermal properties of the material composing the tool are reported in Table 3 . The triangle and square features were used individually in a die sinking machining process on an ultrafine grain aluminum workpiece; the material properties are reported in Table 4. The die sinking process was performed on the $z$ axis from the top surface of the workpiece down to a depth of $150 \mu \mathrm{m}$.

\subsection{Process parameters}

The tests were executed with two different parameters combinations, a first characterized by a lower energy index (Energy:

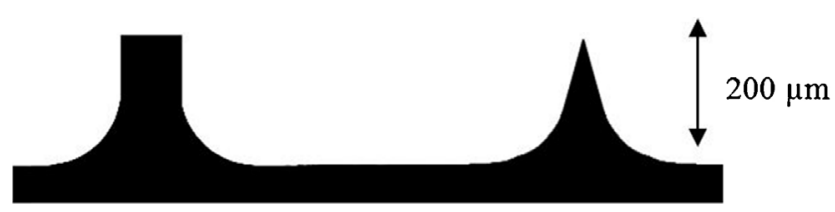

Fig. 3. Tungsten carbide tools

Table 2

Dimensions of the tool features.

\begin{tabular}{lll}
\hline Feature & Base $[\mu \mathrm{m}]$ & Height $[\mu \mathrm{m}]$ \\
\hline Triangle & 100 & 200 \\
Rectangular & 100 & 200 \\
\hline
\end{tabular}

Table 3

Tungsten carbide physical and thermal data.

\begin{tabular}{ll}
\hline Property & Value \\
\hline Melting temperature [K] & 3096 \\
Latent melting heat [J/kg] & 445,000 \\
Vaporization temperature [K] & 6273 \\
Latent heat of vaporization $\mathrm{mol}[\mathrm{kJ} / \mathrm{mol}]$ & 824,000 \\
a.m.u. [ $\mathrm{kg} / \mathrm{mol}]$ & 0.196 \\
Latent heat of vaporization $[\mathrm{J} / \mathrm{kg}]$ & $4,204,082$ \\
Specific heat $[\mathrm{J} / \mathrm{kg} \mathrm{K}]$ & 238 \\
Density [ $\left.\mathrm{kg} / \mathrm{m}^{3}\right]$ & 15,800 \\
\hline
\end{tabular}

Table 4

Aluminum physical and thermal data.

\begin{tabular}{ll}
\hline Property & Value \\
\hline Melting temperature $[\mathrm{K}]$ & 933 \\
Latent melting heat $[\mathrm{J} / \mathrm{kg}]$ & 321,000 \\
Vaporization temperature $[\mathrm{K}]$ & 2792 \\
Latent heat of vaporization $[\mathrm{J} / \mathrm{kg}]$ & $10,530,000$ \\
Specific heat $[\mathrm{J} / \mathrm{kg} \mathrm{K}]$ & 910 \\
Density $\left[\mathrm{kg} / \mathrm{m}^{3}\right]$ & 2700 \\
\hline
\end{tabular}

114; Voltage 60V; Peak Current: 20) and a second one characterized by a higher removal rate due to a higher energy index (Energy: 200; Voltage 90 V; Peak Current: 50). It is important to remark that in Sarix EDM machine, peak current is expressed as an index, its relation with the actual value of current (expressed in Ampère) is correlated to the other process parameters and it is unknown. The only way to obtain an actual value of the current is the direct measurement during each single EDM process. Similarly, the energy level is an index that establishes the shape of the pulse. Some other parameters were kept fixed during the machining: frequency $(100 \mathrm{kHz})$, gain (80), gap (65), regulation (02-01), polarity (-), width (5 $\mu \mathrm{s})$.

For each parameters combination, two repetitions were executed. The first one was aimed at assessing the total number of sparks occurring between the tool and the workpiece during the entire machining. The second one was executed in order to collect patches of discharges (current and voltage waveforms), as described in Section 2, which can then be used to estimate the total amount of energy involved during the machining.

For the selection of the process parameters a hierarchical approach was adopted. It is well known from the literature that the machine parameters governing the erosion process are energy, peak current, voltage, frequency, width, gain, gap, polarity and regulation. In particular, for the voltage parameter, the maximum and minimum values are influenced by the energy level (represented by an index value on the machine). Similarly, the peak current parameter boundaries are set by the voltage and for the same reason the energy parameter itself is supposed to have an influence on the peak current parameter boundaries. Regarding the frequency, it is influenced by the peak current, and for the same reasons it is also influenced by the voltage and by the energy level, as well. Finally, the pulse on time is influenced by the energy level and by the frequency (and for the same reasons it is influenced by the peak current and the voltage as well). Based on these assumptions, three parameters (energy, current, voltage) were varied on two levels. The experimental campaign resulted in a total amount of eight tests.

\subsection{Experimental setup}

After the selection of the process parameters the experimental set up was implemented. A $3 \mathrm{R}^{\circledR}$ clamping system was used to hold the workpiece in order to minimize the positioning misalignment. This system allows for a proper placement of the workpiece thank to a screw based system which can compensate the misalignment in two directions (Fig. 4).

With this device, the alignment was performed on a "trial and error procedure" using a standard cylindrical micro-EDM tool (Ø290 $\mu \mathrm{m})$. Since micro-EDM is an electrically based technology, it is possible to exploit the short circuit occurring when the tool and the workpiece are in contact to measure the misalignment. The $150 \mu \mathrm{m}$ deep die sinking process (for the execution of slits) was then performed while recording peak current and voltage data as explained in Section 3. The machining time was $19.0 \mathrm{~s}$ for the triangular feature and $72.6 \mathrm{~s}$ for the rectangular feature. 


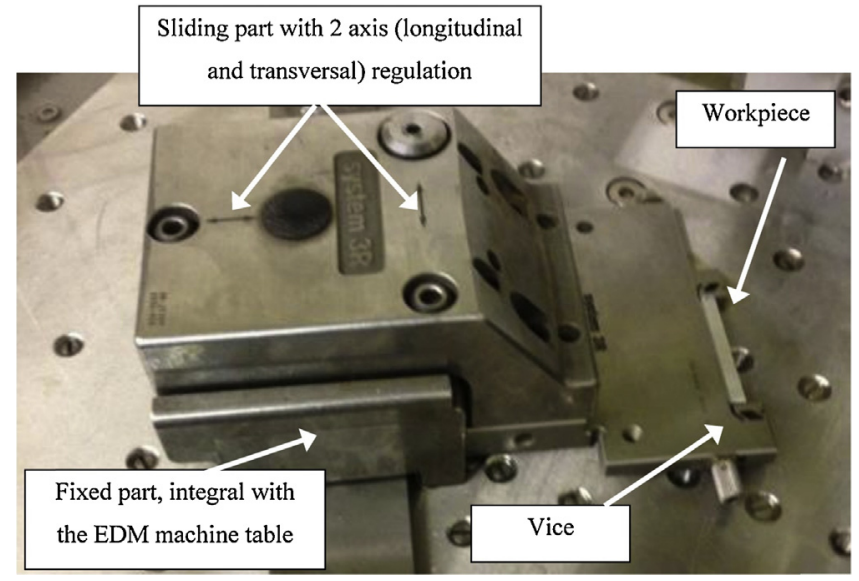

Fig. 4. 3R clamping system.
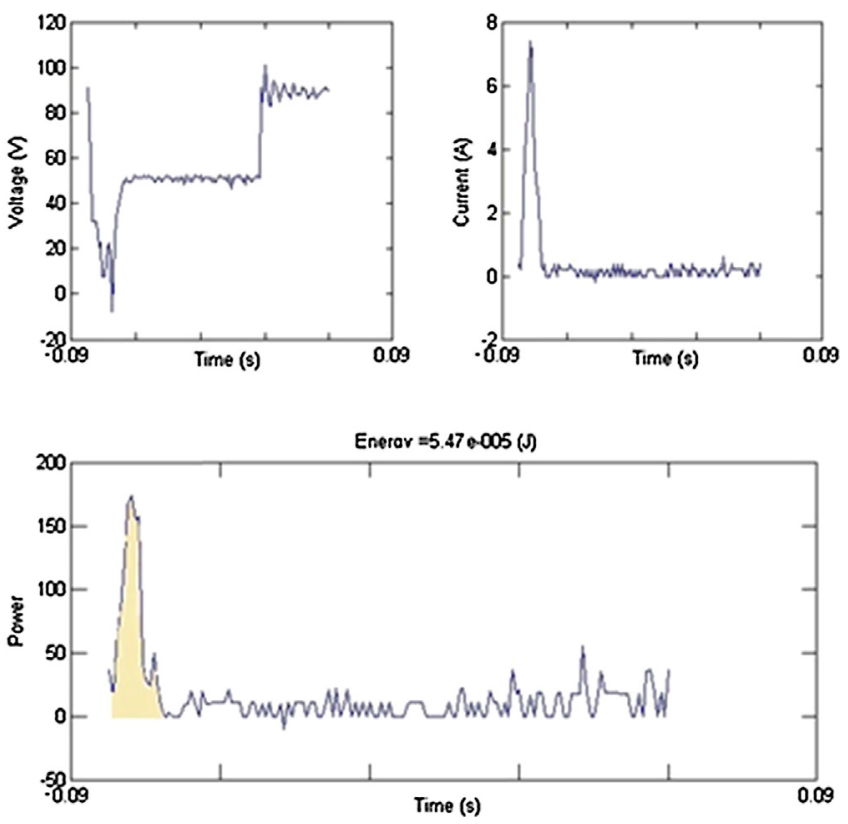

Fig. 5. Current/voltage waveforms and energy calculation.

\subsection{Estimation of the amount of energy}

After the execution of the experimental campaign it was possible to calculate the total amount of energy that occurred during the recorded patches of discharges. As the total number of sparks occurring between tool and workpiece was also recorded, and assuming that nearly the same number of sparks occurred in the two repetitions mentioned in Section 4.1, it was then possible to estimate the total amount of energy that occurred during the entire die sinking process. In Fig. 5 a typical distribution of current and voltage is reported together with the power trend as a function of the time.

Since the energy is distributed between the tool, the workpiece and the dielectric, in order to evaluate the actual distribution of energy, it was decided to estimate the energy effectively lost into the tool and into the workpiece from the volume of material actually removed from the tool and from the workpiece. These volumes were measured using an optical coordinate measuring system, namely the Mitutoyo Quickvision Pro QVC20. Regarding the tool, the volume removed was simply estimated by measuring the dimensions of the features (triangle and square features) before and after the machining. Fig. 6 shows a profile of the triangular and rectangular tools after erosion.

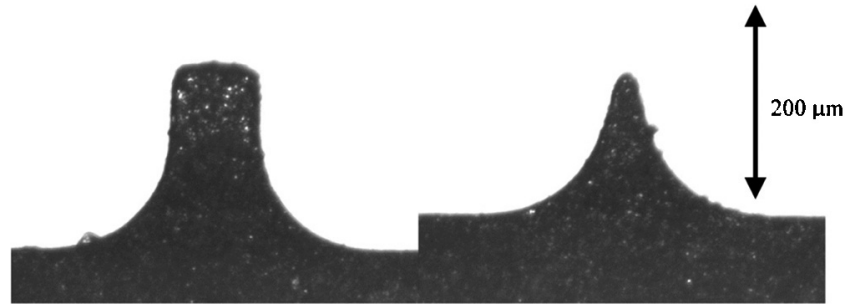

Fig. 6. Tungsten carbide tools after erosion.

For the workpiece, it was necessary to execute a transversal cut for each feature in order to collect reliable information about the depth of the features. For both of the electrodes, the volume removed was estimated by the measurement of the cross-sections' areas and the use of the hypothesis that the wear was constant along the third direction. The multiplication of the area and the length of the third dimension $(2.5 \mathrm{~mm})$ provides with the volume of the electrode.

Based on the information related to the total volumes removed, it is possible to calculate the amount of energy necessary to remove that amount of material using the following theory.

In this experiment, the estimation of the energy (heat, $Q$ ) is based on the definition of specific heat, as reported in Eq. (3) and in Eq. (4):

$Q=c \cdot m \cdot \Delta T$

$Q_{\text {lat }}=\lambda \cdot m$

where $c$ is the specific heat, $m$ is the mass of the material removed from the workpiece/electrode, $\lambda$ is the latent heat of melting or evaporation and $\Delta T$ is the temperature variation between the starting and the final state. Starting from the volume $(V)$ of the material removed from the workpiece/tool, it was possible to calculate the mass $(m)$ of the material removed (knowing the workpiece material density), as reported in Eq. (5):

$m=V \cdot \rho$

where $\rho$ represents the density of the material expressed in $\mathrm{kg} / \mathrm{m}^{3}$.

Since the temperatures reached during the process are considerably higher than the melting temperature (see Section 2), two main phenomena are supposed to take place during the material removal process, both the melting and the vaporization of the material. The following equations simplify the formulation of the problem: Eq. (6) relates to the heat necessary to increase the temperature of the material from the room temperature to the melting temperature $\left(E_{i}\right)$, Eq. (7) expresses the formula of the latent heat necessary to completely melt the material $\left(E_{l, f u s}\right)$, Eq. (8) describes the heat necessary to increase the temperature of the workpiece from the melting to the vaporizing temperature $\left(E_{f}\right)$ and Eq. (9) describes the latent heat of vaporization ( $\left.E_{l, v a p}\right)$.

$E_{i}=c \cdot m \cdot\left(T_{a m b}-T_{f u s}\right)$

$E_{l, f u s}=\lambda_{\text {fus }} \cdot m$

$E_{f}=c \cdot m \cdot\left(T_{f u s}-T_{\text {evap }}\right)$

$E_{l, v a p}=\lambda_{\text {vap }} \cdot m$

During the erosion process the material is not completely vaporized, because a part of the material is only melted and re-solidified into little particles (called debris) removed by the dielectric flushing.

Moreover, a percentage of the melted material is re-solidified on the workpiece and for this reason is not properly removed from the workpiece by the dielectric flushing. This phenomenon has an 
Table 5

Estimation of the energy amount (tool/anode).

\begin{tabular}{lll}
\hline Property & $\begin{array}{l}\text { Triangular } \\
\text { feature }\end{array}$ & $\begin{array}{l}\text { Rectangular } \\
\text { feature }\end{array}$ \\
\hline $\begin{array}{l}\text { Average energy per spark }[\mu \mathrm{J}] \\
\text { Estimated total energy } E[\mathrm{~J}]\end{array}$ & 5.40 & 47.7 \\
Tool's volume removed $\left[\mathrm{mm}^{3}\right]$ & 2.57 & 8.66 \\
Energy to remove the volume & 0.0145 & 0.0759 \\
{$[\mathrm{~J}]:$ min $(0.57 \%) /$ max $(4.7 \%)$} & $0.261 / 0.309$ & $1.36 / 1.61$ \\
Percentage going to the tool: & $10.1 \%$ & $15.7 \%$ \\
min/max & $12.0 \%$ & $18.6 \%$ \\
\hline
\end{tabular}

Table 6

Estimation of the energy amount (workpiece/cathode).

\begin{tabular}{lll}
\hline Property & $\begin{array}{l}\text { Triangular } \\
\text { feature }\end{array}$ & $\begin{array}{l}\text { Rectangular } \\
\text { feature }\end{array}$ \\
\hline $\begin{array}{l}\text { Average energy per spark }[\mu \mathrm{J}] \\
\begin{array}{l}\text { Estimated total energy }[\mathrm{J}] \\
\text { Workpiece's volume removed }\end{array}\end{array}$ & 5.40 & $\begin{array}{l}47.7 \\
{\left[\mathrm{~mm}^{3}\right]}\end{array}$ \\
$\begin{array}{l}\text { Energy to remove the volume } \\
{[\mathrm{J}]: \text { min }(0.06 \%) / \text { max }(0.48 \%)}\end{array}$ & 0.0122 & 8.66 \\
$\begin{array}{l}\text { Percentage going to the } \\
\text { workpiece: } \min / \max \end{array}$ & $0.0299 / 0.0316$ & 0.0579 \\
\hline
\end{tabular}

effect on the volume characteristics of the crater and on the energy amount.

The melted material in fact, can be re-solidified on the workpiece surface because of the temperature decrease caused by the dielectric flushing.

For this reason this material needs to be re-melted and eventually to be re-vaporized in order to be removed by the following sparks. This aspect was then taken into account for the energy estimation procedure. Let $r$ be the percentage of the melted material which is supposed to be re-solidified on the workpiece. For this reason, if the $r$ parameter is equal to 1 all the melted material is considered to be re-solidified on the workpiece. On the contrary, for $r=0$ the material is considered to be completely melted and removed from the workpiece surface.

The total amount of energy required to remove the material from the workpiece can be summarized as follows:

$E_{\text {tot }}=E_{i}+E_{l, f u s}+E_{f}+E_{l, v a p}$

Tables 5 and 6 report the amounts of energy for the tool and workpiece material removal respectively. The results provided here were obtained for the low level energy parameters as those resulted in better, more regular surface finishes and were more easily measured.

As an example, the calculation for the material removed from the tool (triangular shape) is reported as follows. It is possible to assume that the material can be both melted and vaporized [25]. As seen before, the percentage of the material melted and vaporized is included between $0.57 \%$ and $4.78 \%$. For the calculation it is assumed that the percentage of the vaporized material is equal to $0.57 \%$ (the lower boundary). For this reason the total volume of the material removed can be divided in two different contributions, the material effectively vaporized and the material only melted:

$V_{\text {vap }}=V_{\text {tot }} \cdot g=8.27 \times 10^{-14} \mathrm{~m}^{3}$

And for the volume only melted the equation is the following:

$V_{\text {mel }}=V_{\text {tot }} \cdot(1-g)=1.44 \times 10^{-11} \mathrm{~m}^{3}$

Knowing the two amounts of volume it is possible to estimate the corresponding mass:

$m_{\text {vap }}=V_{\text {vap }} \cdot \rho=2.27 \times 10^{-7} \mathrm{~kg}$
Table 7

Summary of energy repartition.

\begin{tabular}{lll}
\hline & Energy repartition (in \%) \\
\cline { 2 - 3 } & $\begin{array}{ll}\text { Triangular } \\
\text { feature }\end{array}$ & $\begin{array}{l}\text { Rectangular } \\
\text { feature }\end{array}$ \\
\hline Tool (anode) & 11.09 & 17.15 \\
Workpiece (cathode) & 1.19 & 1.69 \\
Dielectric & 87.72 & 81.16 \\
\hline
\end{tabular}

$m_{\text {mel }}=V_{\text {mel }} \cdot \rho=1.30 \times 10^{-9} \mathrm{~kg}$

Based on these calculations the four amount of energy involved during the process are reported below:

$E_{i}=0.153 \mathrm{~J}$

$E_{l, f u s}=0.102 \mathrm{~J}$

$E_{f}=0.001 \mathrm{~J}$

$E_{l, v a p}=0.005 \mathrm{~J}$

The total amount of energy necessary to remove the material from the triangular feature with the "gentler parameters combination is reported in Eq. (19). Table 7 resume the data concerning the energy repartition.

$E_{\text {tot }}=E_{i}+E_{l, f u s}+E_{f}+E_{l, v a p}=0.261 \mathrm{~J}$

It is important to remark that the present experimentation is consistent with the literature [1].

\section{Conclusions and future works}

In this paper, a method has been developed for the efficient recording of micro-EDM pulse discharges and has been used in the determination of energy repartition between tool, workpiece and dielectric. Experimental results are in accordance with previous results available in the literature.

The validation of the presented acquisition method will enable the use of information related to energy repartition in the simulation of the micro-EDM process being developed by the authors.

\section{Acknowledgements}

The reported research was partly funded by the Engineering and Physical Sciences Research Council (EPSRC) under the grant $\mathrm{EP} / \mathrm{J} 004901 / 1$.

\section{References}

[1] Fleischer J, Schmidt J, Haupt S. Combination of electric discharge machining and laser ablation in microstructuring of hardened steels. Microsyst Technol 2006;12:697-701.

[2] Egashira K, Morita Y, Hattori Y. Electrical discharge machining of submicron holes using ultrasmall-diameter electrodes. Precis Eng 2010;34:139-44.

[3] Jahan MP. Wong YS, Rahman M. Evaluation of the effectiveness of low frequency workpiece vibration in deep-hole micro-EDM drilling of tungsten carbide. J Manuf Process 2012;14:343-59.

[4] Kibria G, Sarkar BR, Pradhan BB, Bhattacharyya B. Comparative study of different dielectrics for micro-EDM performance during microhole machining of Ti-6Al-4V alloy. Int J Adv Manuf Technol 2010;48:557-70.

[5] Shao B, Rajurkar KP. Micro-EDM pulse energy distribution ratio determination. In: Proceedings of the 8th International Conference on Micro Manufacturing ICOMM. 2013.

[6] Zahiruddin M, Kunieda M. Energy distribution ratio into micro-EDM electrodes. J Adv Manuf Des Syst Manuf 2010;4(6):1095-106.

[7] Obaciu G, Pisarciuc C, Klocke F, Klotz M. Energy consumptions evaluation at electro discharge machining of polycrystalline diamond. Nonconv Technol Rev 2010;3:30-3.

[8] Okada A, Uno Y, Okajima I. Energy distribution in electrical discharge machining with graphite electrode. Memoirs of the Faculty of Engineering, vol. 34(1,2), Okayama University; 2000. p. 19-26. 
[9] Bissacco G, Hansen HN, Tristo G, Valentincic J. Feasibility of wear compensation in micro EDM milling based on discharge counting and discharge population characterization. CIRP Ann - Manuf Technol 2011;60:231-4.

[10] Mahardika M, Mitsui K. A new method for monitoring micro-electric discharge machining processes. Int J Mach Tools Manuf 2008;48:446-58.

[11] Aligiri E, Yeo SH, Tan PC. A new tool wear compensation method based on realtime estimation of material removal volume in micro-EDM. J Mater Process Technol 2010;210:2292-303.

[12] Cogun C, Savsar M. Statistical modelling of properties of discharge pulses in electric discharge machining. Int J Mach Tools Manuf 1990;30(3):467-74.

[13] Singh H. Experimental study of distribution of energy during EDM process for utilization in thermal models. Int J Heat Mass Transf 2012;55:5053-64.

[14] Singh H, Shukla DK. Optimizing electric discharge machining parameters for tungsten-carbide utilizing thermo-mathematical modelling. Int J Therm Sci 2012;59:161-75

[15] Dibitonto DD, Eubank PT, Patel MR, Barrufet MA. Theoretical models of the electrical discharge machining process I. A simple cathode erosion model. J Appl Phys 1989;66(9):4095-103.

[16] Dibitonto DD, Eubank PT, Patel MR, Barrufet MA, Mukund R. Theoretical models of the electrical discharge machining process II. The anode erosion model. J Appl Phys 1989;66(9):4104-11.
[17] Pandey PC, Jilani ST. Plasma channel growth and the re-solidified layer in EDM. Precis Eng 1986;8(2):104-10.

[18] Jilani ST, Pandey PC. Analysis and modeling of EDM parameters. Precis Eng $1982 ; 4: 215-21$.

[19] Van Dijck FS, Dutrè WL. Heat conduction model for the calculation of the volume of molten metal in electric discharges. J Appl Phys 1974;7(6): 899-910.

[20] Salah NB, Ghanem F, Atig KB. Thermal and mechanical numerical modeling of electric discharge machining process. Commun Numer Methods Eng 2008;24(12):2021-34

[21] Singh A, Ghosh AA. Thermo electric model of material removal during electric discharge machining. Int J Mach Tools Manuf 1999;39(4):669-82.

[22] Joshi SN, Pande SS. Thermo-physical modeling of die-sinking EDM process. Manuf Process 2010;12(1):45-56

[23] Izquierdo B, Sanchez JA, Plaza S, Pombo I, Ortega N. A numerical model of the EDM process considering the effect of multiple discharges. Int J Mach Tools Manuf 2009;49:220-9.

[24] Beck JV, Litkouhi B, Clair CRS. Efficient sequential solution of the nonlinear inverse heat conduction problem. Numer Heat Transf 1982;5(3):275-86.

[25] Masuzawa T. State of the Art of Micromachining. CIRP Ann - Manuf Technol 2000;49(2):473-88. 